\title{
FINANCIAMENTO DO ESPORTE OLÍMPICO DE VERÃO BRASILEIRO: MAPEAMENTO INICIAL DO PROGRAMA "BOLSA- ATLETA" (2005-2011)
}

\author{
Amanda Jorge Corrêa \\ Universidade Federal do Paraná, Curitiba, Paraná, Brasil. \\ Marcelo Moraes e Silva \\ Universidade Federal do Paraná, Curitiba, Paraná, Brasil. \\ Fernando Marinho Mezzadri \\ Universidade Federal do Paraná, Curitiba, Paraná, Brasil. \\ Fernando Renato Cavichiolli \\ Universidade Federal do Paraná, Curitiba, Paraná, Brasil.
}

\begin{abstract}
Resumo
A presente pesquisa tem como objetivo realizar um mapeamento inicial de um importante programa do governo federal, de fomento do esporte brasileiro, denominado "Bolsa-Atleta". Para tanto, a fonte utilizada nas análises foram as listagens dos atletas contemplados disponibilizadas no site do Ministério do Esporte, delimitado entre os anos de 2005 a 2011. Dessas fontes foram recortadas as informações referentes às modalidades dos esportes olímpicos de verão, totalizando um número de 9.149 bolsas concedidas. A título de conclusão, a pesquisa aponta que o "BolsaAtleta", apesar de trazer inúmeros benefícios ao esporte olímpico brasileiro, ainda reflete uma pirâmide de alicerce estreito, com instabilidades que o fragilizam ao ponto de não conseguir manter-se em "pé".
\end{abstract}

Palavras chave: Esportes. Financiamento governamental. Atletas.

\section{Introdução}

Instituída em 2004, com a promulgação da Lei no 10.891 , e regulamentada pelo Decreto n- 5.342, a "Bolsa-Atleta" trata-se de um programa de financiamento do governo federal aos atletas de rendimento do país. Sua intencionalidade é destinar recursos financeiros para a manutenção esportiva do atleta (BRASIL, 2005). Esse projeto foi encaminhado, no ano de 2000, pelo então deputado Agnelo Queiroz, que viria a se tornar o primeiro ministro do Esporte quando essa pasta foi criada em 2003, no mandato do ex-presidente Luiz Inácio Lula da Silva.

Desde a época da tramitação do projeto de lei na Câmara dos Deputados, justificava-se a necessidade de maior investimento governamental para fomentar o desenvolvimento do esporte, como um dever constitucional que o país cumpria insuficientemente. 
Tal preocupação ganhou maior significação após os Jogos Olímpicos de Sidney, em 2000, retratando um subestimado desempenho dos atletas brasileiros, que não chegaram a conquistar nenhuma medalha de ouro. Como apontou Guimarães (2009), esse fato promoveu um debate no seio da sociedade civil brasileira.

Atualmente a esfera pública arca com diversos programas buscando sanar os notórios problemas de financiamento do esporte. Dentre eles destaca-se o programa "BolsaAtleta". De acordo com Corrêa (2013), a "Bolsa-Atleta" consiste de um financiamento que contemplou inicialmente quatro níveis de bolsa: I) categoria Olímpica/Paraolímpica ${ }^{1}$; II) categoria Internacional ${ }^{2}$; III) categoria Nacional $^{3}$ e, por fim, IV) categoria Estudantil ${ }^{4}$. Todas requerem que o atleta tenha idade mínima de 14 anos completos. Incluídas posteriormente pela Lei no 7.802 , de 13 de setembro de 2012, que altera a Lei no 10.891 , de 9 de julho de 2004, as categorias de Base $^{5}$ e Pódio ${ }^{6}$. Os respectivos valores, atualizados para cada categoria de bolsa, são: a) Base: R\$ 370,00; b) Estudantil: R\$ 370,00; c) Nacional: R\$ 925,00; d) Internacional: R\$ 1.850,00; e) Olímpico e Paraolímpico: R \$ 3.100,00; f) Pódio: até R\$15.000,00. Outro ponto de destaque na Lei é que, em sua primária publicação, não permitia que atletas que possuíssem qualquer patrocínio e/ou salário se inscrevessem no programa, condição que foi modificada em 2012, quando atletas em tais condições passaram a poder receber o beneficio governamental.

Nesse sentido, o presente artigo pretende responder às seguintes perguntas: Como se configura esse programa federal chamado "Bolsa-Atleta"? Quais são suas características por modalidade esportiva, sexo, nível de bolsa e distribuição por região do país? Tais perguntas são o eixo central deste estudo, pois as respostas podem contribuir para o entendimento do programa de fomento governamental e com isso proporcionar o aprimoramento desse programa federal. Como recorte específico, o presente trabalho selecionou somente as modalidades esportivas olímpicas de verão, excluindo os atletas

\footnotetext{
${ }^{1}$ Destinado aos atletas que participaram de uma edição dos Jogos Olímpicos/Paraolímpicos e que continuem treinando para competições internacionais.

${ }^{2}$ Destinado aos atletas que participaram da delegação nacional respectiva ao seu esporte, representando o país em campeonatos sul-americanos, pan-americanos e mundiais. Atletas que conquistaram as três primeiras colocações em competições consideradas máximas pela respectiva confederação e que continuem treinando para competições em âmbito internacional.

3 Destina-se aos atletas que atingiram as três primeiras colocações em competição indicada pela entidade nacional de administração de desporto, bem como, para aqueles que se encontrem nas primeiras três colocações do ranking nacional de sua modalidade, também indicada pela entidade nacional de administração do desporto.

${ }^{4}$ Destina-se aos atletas que participaram dos Jogos estudantis ou Universitários, bem como ter obtido os três primeiros lugares em modalidade individual, ou ser considerado melhor atleta em competição de modalidades coletivas e que continuem treinando para competições nacionais oficiais. Esta categoria delimita a inscrição do atleta até 20 anos de idade.

${ }^{5}$ Destina-se aos atletas que participaram com destaque em competições organizadas pela entidade nacional de desporto, bem como, tenham conquistado as três primeiras colocações em competição em esportes individuais, ou dez primeiros lugares (por sexo) em modalidades coletivas, e que continuem treinando para competições nacionais oficiais. Esta categoria delimita a inscrição do atleta até 19 anos de idade.

${ }^{6}$ Destina-se aos atletas de modalidades individuais olímpicas e paraolímpicas que de acordo com critérios estabelecidos pelas entidades máximas nacionais $(\mathrm{COB} / \mathrm{CPB})$ e que estejam vinculados ao programa atletapódio e que recentemente foram incorporados no denominado "Plano Brasil Medalhas".
} 
contemplados dos esportes de inverno, paraolímpicos e de modalidades que não fazem parte do quadro olímpico.

\section{Decisões metodológicas}

Henry et al. (2005), ao analisar o contexto internacional, observou que existe uma necessidade de padronização nos métodos de investigação utilizados para fazer estudos sobre políticas de esporte. Os autores lembram que na mesma proporção existe uma limitação de estudos com dados disponíveis e quantificáveis sobre as políticas de esporte. Se isso ocorre no cenário internacional, tais fatores são ainda mais contundentes no cenário brasileiro, conforme pode ser visualizado no estudo de Starepravo (2011). Contudo, apesar da pouca quantidade, como apontado por Henry et al. (2005), tem-se visto um desenvolvimento considerável, desde 2000 , de pesquisas sobre políticas de esporte, principalmente por conta do desejo dos pesquisadores em explicar e compreender as causas de sucesso e/ou fracasso de alguns países em competições esportivas internacionais (GREEN; OAKLEY, 2001; GREEN E HOULIHAN, 2005; HOULIHAN, 2008).

Para atender a esses fins, dois instrumentos de pesquisa foram desenvolvidos a fim de coletar os dados do programa "Bolsa-Atleta": (1) a definição de indicadores da política propriamente dita; (2) a elaboração de uma matriz analítica para a política implementada (CORRÊA, 2013). A seleção da amostra foi baseada em: (1) medidores de esforços das políticas de esporte - financiamento, metas e diretrizes, planejamento, recursos humanos; (2) medidores de realização - estrutura, implementação, acompanhamento, avaliação, divulgação, produção do conhecimento e perenidade. Cada um desses indicadores deve conter uma relação de questões que serviram de fundamento para as análises qualitativas e quantitativas do presente artigo.

Após estabelecer esses instrumentos, teve início a transposição dos dados expostos no site do Ministério do Esporte $^{7}$, apresentando a listagem de atletas que obtiveram a concessão do benefício. No início da investigação, foi detectado o total de 37 modalidades olímpicas ${ }^{8}$. Reconhece-se que os esportes que completam esse total participaram das Olimpíadas de 2004, 2008 (último ano para as modalidades Beisebol e Softbol), 2012 (não houve inclusão de modalidades para a realização da competição em Londres) e da edição por vir, em 2016, sendo que para essa edição foram inclusos o Golfe e o Rugby.

A apresentação das informações de atletas contemplados no site em 2005 era um meio de distinção das informações para a pesquisa, pois apresentava-se através dos órgãos federativos, confederativos e associações responsáveis pelas modalidades inscritas. A partir de 2008, tal configuração se modificou, omitindo as cidades dos atletas e posteriormente as Unidades Federativas. Tais dados foram retirados do site e realocados em novos modelos de tabela, selecionados de acordo com o critério da pesquisa. Após todos os anos serem catalogados partiu-se para o esboço do tratamento estatístico. Os dados foram

\footnotetext{
${ }^{7}$ Disponível em: http://www.esporte.gov.br/snear/bolsaAtleta/lista_contemplados.jsp

${ }^{8}$ As modalidades elencadas nesta pesquisa são: Atletismo; Badminton; Basquetebol; Beisebol e Softbol; Boxe; Canoagem; Ciclismo; Desportos Aquáticos (Natação, Nado sincronizado, Saltos Ornamentais, Polo Aquático, Maratona Aquática); Esgrima; Futebol de Campo; Ginástica Artística; Ginástica Rítmica; Ginástica de Trampolim; Golfe; Handebol; Hipismo; Hóquei Sobre a Grama; Judô; Levantamento de Peso; Luta Greco-Romana; Luta Livre; Pentatlo Moderno; Remo; Rugby; Taekwondo; Tênis, Tênis de Mesa; Tiro com Arco; Tiro Esportivo; Triatlon; Voleibol; Vôlei de Praia; e, por fim, Vela e Motor.
} 
transpostos para uma planilha do programa Excel Microsoft Office e preencheram o total de 9.149 bolsas concedidas. Foi preciso estruturar as informações em uma matriz com nove colunas de informações:

1) Primeira coluna: refere-se à modalidade esportiva (37 reconhecidas dentro da pesquisa).

2) Segunda: contém o nome do atleta.

3) Terceira: cita o nível da bolsa pertencente (categorias: Olímpica, Paraolímpica, Internacional, Nacional, Estudantil e Base).

4) Quarta: relativa à cidade (informada nos primeiros anos do programa, até 2007).

5) Quinta: dispõe as Unidades Federativas (preenchida até o ano de 2008).

6) Sexta: informa o sexo do atleta.

7) Sétima: compreende a região (também limitada ao ano de 2008).

8) Oitava: inclui o ano de concessão.

9) Nona: abarca o escopo de valores para cada bolsa (não será utilizada nesta pesquisa $\left.^{9}\right)$.

\section{Resultados e discussões}

Essas primeiras análises se configuram como um panorama do que se obteve em primeira instância com os dados. Foi possível notar que houve um afunilamento dentro do programa. No primeiro ano de execução, que foi em 2005, até o de 2009 há diversos esportes não olímpicos e não paraolímpicos contemplados. Porém, para a listagem do ano de 2010, promulgada em 2011, foi aberta uma Portaria contemplando 89 atletas das modalidades consideradas não olímpicas/paraolímpicas. O mesmo ocorre para os dados relativos ao ano de 2011, que contempla apenas 609 atletas dessas modalidades. Tal fato se deve à alteração da Lei no 10.891, que instituiu a "Bolsa-Atleta", pelo Decreto no 12.395, de 16 de março de 2011, que acrescentou o $\S 4^{\circ}$ ao art. 1ํ da Lei:

A concessão do benefício para os participantes de modalidades individuais e coletivas que não fizerem parte do programa olímpico ou paraolímpico fica limitada a $15 \%$ (quinze por cento) dos recursos orçamentários disponíveis para a Bolsa-Atleta (BRASIL, 2011).

Essa predominância dos esportes olímpicos de verão pode ser observada na tabela comparativa entre o total amostral por ano desse recorte e o total de bolsas concedidas:

\footnotetext{
${ }^{9}$ A despeito de se ter o interesse em investigar a projeção de renovações na bolsa para os atletas, bem como o crescimento deste programa, nesta pesquisa não se poderá inferir a respeito.
} 
Tabela 1. Comparação da concessão de bolsas pelo ME e recortados na pesquisa.

\begin{tabular}{c|c|c|c}
\hline Ano & $\begin{array}{c}\text { Total de } \\
\text { Bolsas Es- } \\
\text { porte } \\
\text { Olímpico }\end{array}$ & $\begin{array}{c}\text { \% da } \\
\text { amostra } \\
\text { compara- } \\
\text { da ao total }\end{array}$ & $\begin{array}{c}\text { Total } \\
\text { de } \\
\text { Bolsas }\end{array}$ \\
\hline $\mathbf{2 0 0 5}$ & 493 & $50,56 \%$ & 975 \\
$\mathbf{2 0 0 6}$ & 379 & $44,38 \%$ & 854 \\
$\mathbf{2 0 0 7}$ & 948 & $43,67 \%$ & 2.171 \\
$\mathbf{2 0 0 8}$ & 1.374 & $43,86 \%$ & 3.133 \\
$\mathbf{2 0 0 9}$ & 724 & $24,48 \%$ & 2.958 \\
$\mathbf{2 0 1 0}$ & 2.067 & $56,55 \%$ & 3.655 \\
$\mathbf{2 0 1 1}$ & 3.164 & $63,31 \%$ & 4.998 \\
Total & 9.149 & $48,81 \%$ & 18.744 \\
\hline
\end{tabular}

Nota-se que nos dois últimos anos, após a alteração da Lei, mais da metade das bolsas se encontram destinadas aos esportes olímpicos de verão. Provavelmente tais alterações devem refletir a escolha do Brasil para sediar os jogos de 2016 e a meta em projetar o país entre os dez melhores nas Olimpíadas do Rio de Janeiro.

O gráfico a seguir detalha o total de bolsas concedidas em todo o período analisado (2005-2011) para cada modalidade esportiva: 


\section{Gráfico 1. Distribuição do total de bolsas para as 37 modalidades esportivas.}

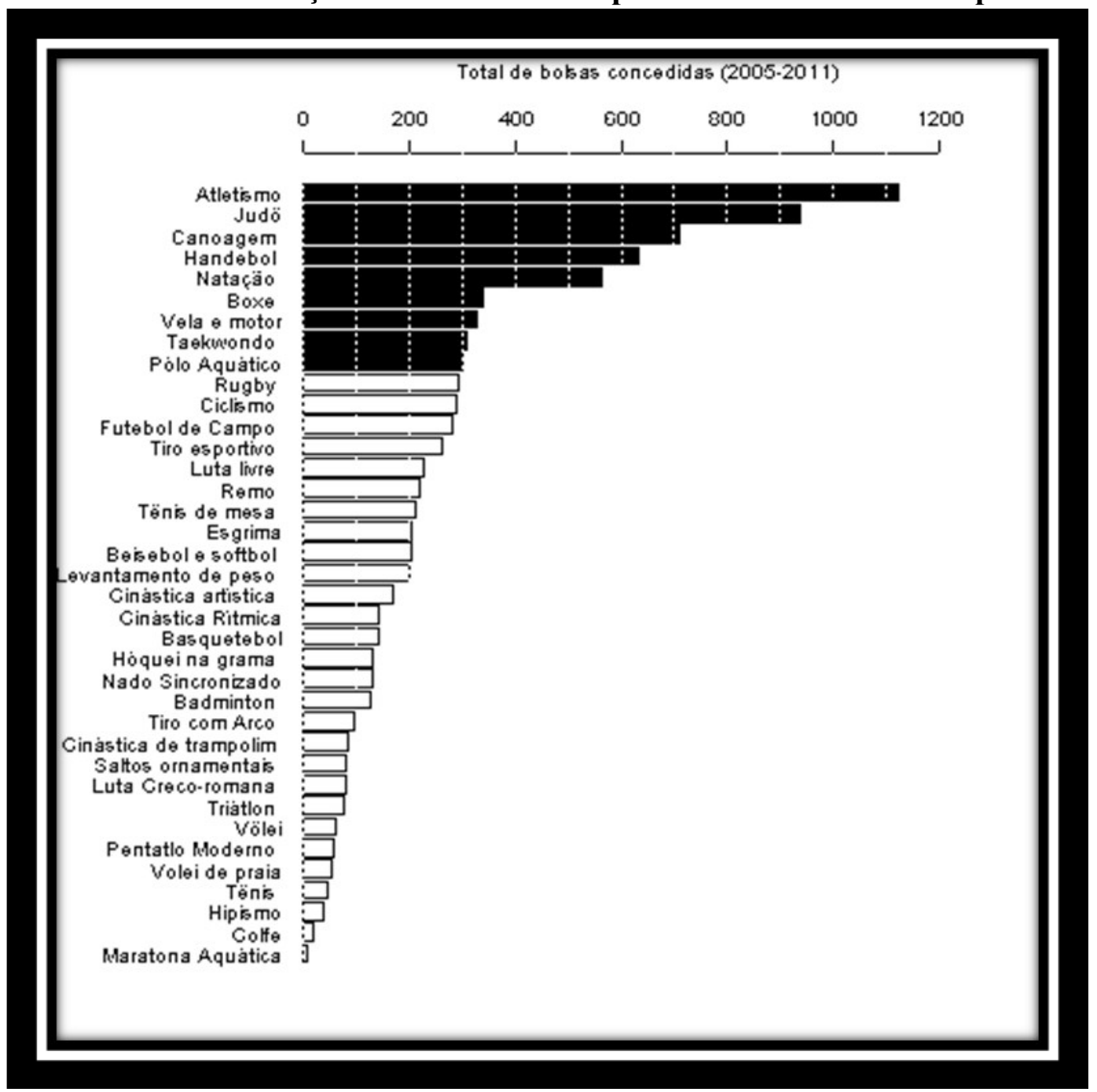

Pode-se reparar que o Atletismo é o esporte que contém a maior quantidade de bolsas concedidas (1.126). Tal número de bolsas deve-se ao fato de ser uma modalidade esportiva com inúmeras provas. Lógica que também vale para a Natação, que está em quinto lugar no número de benefícios concedidos. O Judô também contém uma grande quantidade, com 937, este provavelmente segue como segundo maior no ranking da concessão de bolsas por ter maior estrutura no país, visto que o Brasil sempre está conquistando importantes colocações no cenário internacional. Já em terceiro lugar surge um caso interessante, a Canoagem, esporte sem muita tradição no país, sem um histórico de conquistas no cenário internacional. Essa modalidade teve, no período da amostragem, concedidas 712 bolsas, contudo apresentou a maior parte do seu crescimento nos últimos dois anos do programa.

Nas quatro últimas posições encontram-se três modalidades consideradas de elite: Tênis, Hipismo e Golfe. Acredita-se que isso pode ter ocorrido pelo fato de esses esportes serem relacionados a grupos sociais abastados, o que pode contribuir para os atletas (sen- 
do eles pertencentes a esses grupos ou não) não buscarem essa subvenção governamental. No caso do Golfe, outro ponto que pode ter contribuído para o pequeno número de bolsas concedidas é o seu retorno recente ao grupo de modalidades olímpicas. No caso da Maratona Aquática, o número reduzido de bolsas é compreensível pelas próprias características da modalidade e pela forma como se configuram suas competições.

Em relação aos níveis de bolsa pode-se inferir que sete esportes nunca foram contemplados na categoria Olímpica: Badminton, Basquetebol, Beisebol e Softbol, Ginástica de Trampolim, Hóquei sobre a Grama, Polo Aquático e Vôlei. Rugby e Golfe estão exclusos por não serem esportes olímpicos no período que foi realizado o levantamento. Todavia, Badminton, Beisebol e Softbol, Ginástica de Trampolim e Hóquei sobre a Grama nunca tiveram representantes brasileiros participando dos Jogos Olímpicos, por esse motivo seus atletas não podem concorrer à bolsa em tal nível. Já o Polo Aquático, apesar de ter participado dos Jogos Olímpicos (última participação em Los Angeles, 1984), apresenta a mesma configuração dos citados acima, afinal esses esportes não são de prática corriqueira no país. Inversamente, têm-se os casos do Basquetebol e do Vôlei, duas modalidades bem tradicionais no Brasil, e a não concessão da bolsa Olímpica acontece principalmente por eles possuírem uma grande estrutura, que envolve patrocinadores, uma base profissional e ligas/campeonatos organizados.

Em termos globais, as bolsas concedidas pelo Ministério do Esporte estão distribuídas por categorias de bolsa da seguinte maneira:

Tabela 2. Distribuição de frequência total das bolsas concedidas para a variável "categoria de bolsa".

\begin{tabular}{c|c|c|c|c|c|c|c|c|c|c|}
\hline $\begin{array}{c}\text { Total } \\
\text { Amo } \\
\text { stral }\end{array}$ & $\begin{array}{c}\text { Total } \\
\text { Olím- } \\
\text { pico }\end{array}$ & $\begin{array}{c}\text { Total } \\
\text { Olím- } \\
\text { pico } \\
\%\end{array}$ & $\begin{array}{c}\text { Total } \\
\text { Interna } \\
\text { cional }\end{array}$ & $\begin{array}{c}\text { Total } \\
\text { Interna } \\
\text { cional } \\
\%\end{array}$ & $\begin{array}{c}\text { Total } \\
\text { Naci } \\
\text { onal }\end{array}$ & $\begin{array}{c}\text { Total } \\
\text { Naci } \\
\text { onal } \\
\%\end{array}$ & $\begin{array}{c}\text { Total } \\
\text { Estu- } \\
\text { dantil }\end{array}$ & $\begin{array}{c}\text { Total } \\
\text { Estu- } \\
\text { dantil } \\
\%\end{array}$ & $\begin{array}{c}\text { Total } \\
\text { Base }\end{array}$ & $\begin{array}{c}\text { Total } \\
\text { Base } \\
\%\end{array}$ \\
\hline $\begin{array}{c}9.14 \\
9\end{array}$ & 348 & $\begin{array}{c}\mathbf{3 , 8 0} \\
\%\end{array}$ & 2.536 & $\mathbf{2 7 , 7 2 \%}$ & $\mathbf{5 . 1 7 4}$ & $\begin{array}{c}56,55 \\
\%\end{array}$ & $\mathbf{8 7 6}$ & $\begin{array}{c}\mathbf{9 , 5 7} \\
\%\end{array}$ & $\mathbf{2 1 5}$ & $\begin{array}{c}\mathbf{2 , 3 5} \\
\%\end{array}$ \\
\hline
\end{tabular}

As categorias Estudantil e Base, quando somadas, apresentam 19 esportes contemplados e um total de 1.091 bolsas concedidas pelo programa. As categorias Internacional e Nacional foram preenchidas em todas as modalidades, comprovando que o investimento se faz principalmente sobre os atletas que se encontram em nível intermediário de competição. Podem-se resumir tais pontos através da representação a seguir: 
Figura 1. Balança do financiamento esportivo olímpico do programa "Bolsa-Atleta"

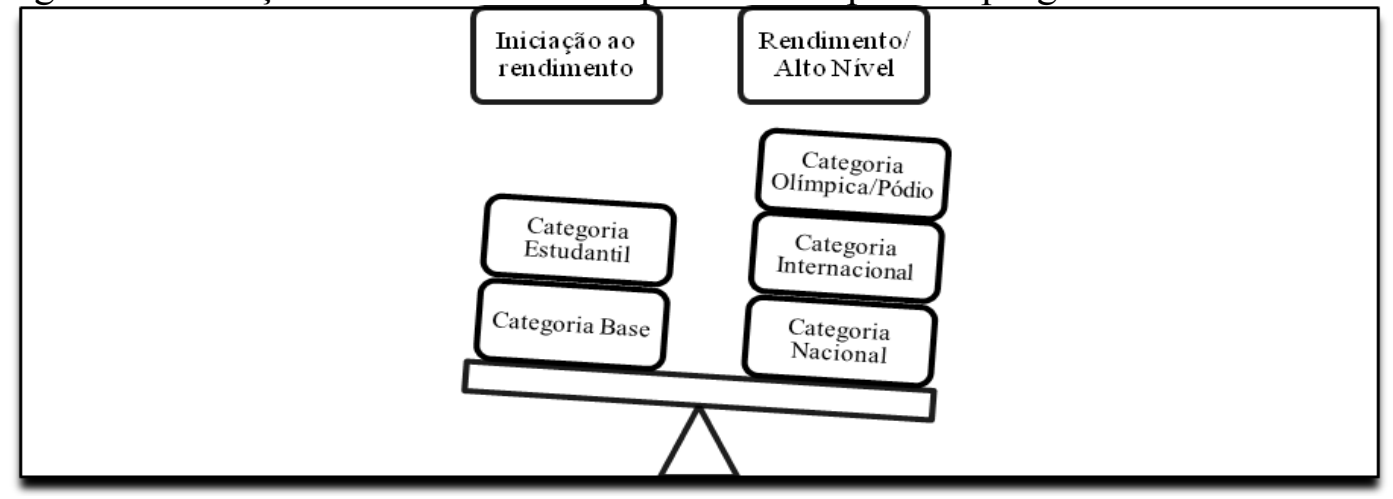

Nota-se que nesse esquema a balança se encontra favorável às categorias mais altas de bolsa, isto é, esferas nas quais a especialização na busca por um rendimento é maior, enquanto as menores categorias de bolsa, aos níveis de iniciação esportiva em performance, estão em um patamar desfavorecido. Não há um equilíbrio entre elas, ou seja, o alicerce do sistema esportivo que deveria alimentar as categorias conseguintes de bolsa não se apresenta em "peso" para reverter esse quadro.

Em relação às categorias de bolsa, é possível pensar num esquema piramidal, onde se tem um financiamento estreito para a iniciação esportiva na base da pirâmide. Seguido por uma lateral mais larga preenchida pelos atletas que foram absorvidos para uma especialização do treinamento em nível de rendimento. Já no topo da pirâmide novamente se apresenta um estreitamento, visto que contempla uma quantidade pequena de atletas que conseguem galgar o nível Olímpico. Como exemplifica o esquema abaixo:

Figura 2. Diagrama do financiamento esportivo através das categorias de bolsa dos espor-

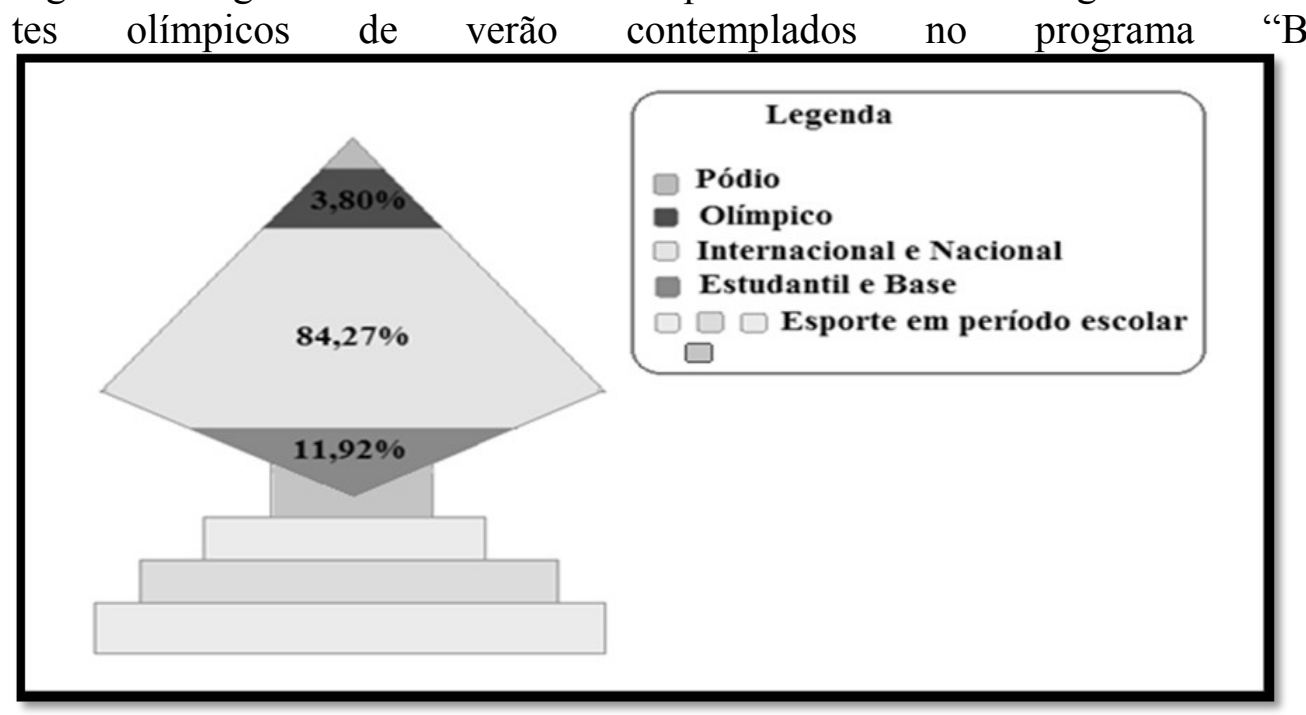

É necessário explicar o que vem a ser a pirâmide formada pelos retângulos que "alimenta" o esquema piramidal constituído pelos valores porcentuais das bolsas. Este designa o entendimento de que os atletas beneficiados nas categorias Base e Estudantil 
representam um enquadramento em um nível de especialização esportiva e não são a base do esporte educacional (entendido como esporte em período de escolarização, no qual há etapas da iniciação esportiva), mas sim o topo desta conjuntura pelas quais é necessário que as crianças transponham para chegar àquele patamar de performance.

Nota-se que tal configuração é de certa forma excludente. Como a base da pirâmide encontra-se estreita, ela acaba por não abarcar a totalidade de modalidades olímpicas do país. Os dados indicam que a pirâmide esportiva brasileira na verdade tem um formato geométrico disforme, tendendo mais ao aspecto de um losango do que piramidal, não tendo uma base que o sustente. Acredita-se que ela deveria apresentar um alicerce mais largo, onde houvesse um maior investimento na iniciação esportiva ao alto nível (leia-se bolsa Estudantil) e principalmente um maior incremento na categoria de Base, para que assim possa haver uma maior renovação e passagem de atletas aos graus maiores de competição. O sistema esportivo ao apresentar semelhanças ao modelo exposto permite afirmar que com um alicerce estreito não há estabilidade nessa estrutura e a qualquer momento ela poderá ruir. Por esse motivo é que ele não consegue manter-se em "pé", quanto mais cumprir as expectativas que estão sendo criadas em relação a 2016.

Dando sequência à análise, a tabela a seguir trata da distribuição por sexo das modalidades esportivas recortadas nesta pesquisa:

Tabela 3. Distribuição de bolsas absolutas e percentuais, por sexo, para cada modalidade esportiva.

\begin{tabular}{c|c|c|c|c}
\hline \multicolumn{5}{c}{ S } \\
e \\
X \\
O \\
\hline Modalidades & $\begin{array}{c}\text { Femini- } \\
\text { no }\end{array}$ & $\begin{array}{c}\text { Feminino } \\
\%\end{array}$ & Masculino & $\begin{array}{c}\text { Masculino } \\
\%\end{array}$ \\
\hline Atletismo & 514 & $45,65 \%$ & 612 & $54,35 \%$ \\
Badminton & 56 & $44,44 \%$ & 70 & $55,56 \%$ \\
Basquetebol & 65 & $46,43 \%$ & 75 & $53,57 \%$ \\
Beisebol e Softbol & 62 & $30,69 \%$ & 140 & $69,31 \%$ \\
Boxe & 120 & $35,29 \%$ & 220 & $64,71 \%$ \\
Canoagem & 180 & $25,28 \%$ & 532 & $74,72 \%$ \\
Ciclismo & 94 & $32,75 \%$ & 163 & $56,79 \%$ \\
Esgrima & 84 & $41,18 \%$ & 120 & $58,82 \%$ \\
Futebol de Campo & 270 & $94,08 \%$ & 17 & $5,92 \%$ \\
Ginástica Artística & 53 & $31,74 \%$ & 114 & $68,26 \%$ \\
Ginástica Rítmica & 142 & $99,30 \%$ & 1 & $0,70 \%$ \\
Ginástica de Trampolim & 42 & $50,00 \%$ & 42 & $50,00 \%$ \\
Golfe & 4 & $25,00 \%$ & 12 & $75,00 \%$ \\
Handebol & 311 & $49,21 \%$ & 321 & $50,79 \%$ \\
Hipismo & 10 & $28,57 \%$ & 25 & $71,43 \%$ \\
& & & &
\end{tabular}




\begin{tabular}{|c|c|c|c|c|}
\hline Hóquei sobre a Grama & 57 & $43,85 \%$ & 73 & $56,15 \%$ \\
\hline Judô & 451 & $48,13 \%$ & 486 & $51,87 \%$ \\
\hline Levantamento de peso & 57 & $28,36 \%$ & 143 & $71,14 \%$ \\
\hline Luta Greco-Romana & 14 & $17,72 \%$ & 65 & $82,28 \%$ \\
\hline Luta Livre & 89 & $39,56 \%$ & 163 & $72,44 \%$ \\
\hline Maratona Aquática & 4 & $80,00 \%$ & 1 & $20,00 \%$ \\
\hline Nado Sincronizado & 127 & $99,22 \%$ & 1 & $0,78 \%$ \\
\hline Natação & 253 & $44,94 \%$ & 310 & $55,06 \%$ \\
\hline Pentatlo Moderno & 24 & $42,11 \%$ & 33 & $57,89 \%$ \\
\hline Polo Aquático & 137 & $45,51 \%$ & 163 & $54,15 \%$ \\
\hline Remo & 65 & $29,68 \%$ & 154 & $70,32 \%$ \\
\hline Rugby & 87 & $29,90 \%$ & 204 & $70,10 \%$ \\
\hline Saltos Ornamentais & 41 & $50,62 \%$ & 40 & $49,38 \%$ \\
\hline Tae kwon do & 138 & $44,95 \%$ & 169 & $55,05 \%$ \\
\hline Tênis & 25 & $55,56 \%$ & 20 & $44,44 \%$ \\
\hline Tênis de Mesa & 88 & $41,90 \%$ & 122 & $58,10 \%$ \\
\hline Tiro com Arco & 30 & $31,25 \%$ & 66 & $68,75 \%$ \\
\hline \multicolumn{5}{|c|}{$\mathbf{S}$} \\
\hline \multicolumn{5}{|c|}{$\mathbf{e}$} \\
\hline \multicolumn{5}{|c|}{$\mathbf{X}$} \\
\hline \multicolumn{5}{|c|}{$\mathbf{0}$} \\
\hline Modalidades & $\begin{array}{c}\text { Femini- } \\
\text { no }\end{array}$ & $\begin{array}{c}\text { Feminino } \\
\% \\
\end{array}$ & Masculino & $\begin{array}{c}\text { Masculino } \\
\% \\
\end{array}$ \\
\hline Tiro Esportivo & 79 & $30,27 \%$ & 182 & $69,73 \%$ \\
\hline Triátlon & 26 & $34,21 \%$ & 50 & $65,79 \%$ \\
\hline Vela e Motor & 97 & $29,48 \%$ & 232 & $70,52 \%$ \\
\hline Vôlei & 25 & $41,67 \%$ & 35 & $58,33 \%$ \\
\hline Vôlei de Praia & 24 & $45,28 \%$ & 29 & $54,72 \%$ \\
\hline
\end{tabular}

Nota-se que 10 modalidades apresentam configuração similar ao total por ano para os sexos com uma diferença média de 13,26\%, com variação mínima de 9,43\% e variação máxima de 17,65\%, a saber: Badminton, Esgrima, Hóquei sobre a Grama, Natação, Pentatlo Moderno, Tae kwon do, Tênis, Tênis de Mesa e Vôlei (quadra e praia). Em outros 16 esportes a quantidade de mulheres e homens é discrepante, apresentando uma diferença média de 40,10\%, com variação mínima de $24,04 \%$ e máxima de 64,56\% para o sexo masculino em relação ao feminino. São eles: Beisebol e Softbol, Boxe, Canoagem, Ciclismo, Ginástica Artística, Golfe, Hipismo, Levantamento de Peso, Luta Greco-Romana, Luta Livre, Remo, Rugby, Tiro com Arco, Tiro Esportivo, Triátlon, Vela e Motor. Apenas quatro modalidades contemplam mais mulheres, sendo duas de prática mais ligadas ao sexo feminino (Ginástica Rítmica e Nado Sincronizado) as outras duas são o Futebol de Campo e a Maratona Aquática. Esses esportes apresentam uma diferença 
média entre os sexos de $86,77 \%$, com variação para valores mínimos de 60,00\% e máximos de $98,60 \%$.

Deve-se destacar aqui o Futebol de Campo, que apresenta uma alta quantidade de atletas do sexo feminino. As mulheres praticantes dessa modalidade, diferentemente dos atletas masculinos, necessitam do subsídio, pelo fato de haver uma sistematização diferenciada desse esporte no país. Porém, o feminino apresenta um tácito crescimento no país inerente à sua história, com jornadas esportivas marcadas por uma forte presença em pódio Olímpico, conquistando o 2o lugar nas Olimpíadas de Atenas (2004) e Pequim (2008). Já o Atletismo, Basquetebol e Polo Aquático, por destoarem pouco, ainda não configuram uma equivalência entre os sexos, apresentando uma diferença média de $8,16 \%$. Por fim, os esportes mais equiparados entre os sexos foram quatro, com diferença média de 2,18\%. São eles: Ginástica de Trampolim, Handebol, Judô e Saltos Ornamentais.

Tal análise relata o fato de haver predominância de modalidades com uma grande diferença da inserção do sexo feminino no esporte, o que permite afirmar que o sexo masculino ainda é dominante dentro das práticas esportivas brasileiras. Esse dado chama a atenção e merece um alerta, pois pesquisadores estrangeiros, como, por exemplo, os britânicos Simon Shibli e Jerry Bingham (2008), apontam que uma medalha olímpica no feminino custa bem mais barato que uma medalha masculina.

O último diagnóstico que se adentra dentro deste mapeamento inicial é sobre as regiões geográficas do país. Entendendo a importância de que um esclarecimento sobre a distribuição espacial da maioria de atletas que visam o rendimento favorece um maior planejamento para um investimento mais eficaz nas modalidades que possuem uma adesão regional. Um polo pode ser fomentado através de corretas políticas públicas para o esporte.

Tabela 4. Distribuição absoluta e percentual, por ano, dos atletas beneficiados, por regiões do país.

\begin{tabular}{c|c|c|c|c|c|c|c|c|c|c|c}
\hline Ano & $\begin{array}{c}\text { Total } \\
\text { Amostral }\end{array}$ & Norte \% & Norte & $\begin{array}{c}\text { Nordeste } \\
\mathbf{\%}\end{array}$ & Nordeste & $\begin{array}{c}\text { Centro- } \\
\text { Oeste \% }\end{array}$ & $\begin{array}{c}\text { Centro- } \\
\text { Oeste }\end{array}$ & $\begin{array}{c}\text { Sudeste } \\
\text { \% }\end{array}$ & Sudeste & Sul \% & Sul \\
\hline $\mathbf{2 0 0 5}$ & 493 & $1,22 \%$ & 6 & $11,16 \%$ & 55 & $5,68 \%$ & 28 & $62,47 \%$ & 308 & $19,47 \%$ & 96 \\
$\mathbf{2 0 0 6}$ & 379 & $1,06 \%$ & 4 & $11,35 \%$ & 43 & $7,12 \%$ & 27 & $62,01 \%$ & 235 & $18,47 \%$ & 70 \\
$\mathbf{2 0 0 7}$ & 948 & $2,37 \%$ & 19 & $12,59 \%$ & 115 & $7,74 \%$ & 74 & $56,35 \%$ & 541 & $20,95 \%$ & 199 \\
$\mathbf{2 0 0 8}$ & 1374 & $2,69 \%$ & 38 & $8,78 \%$ & 124 & $5,80 \%$ & 82 & $61,00 \%$ & 862 & $18,97 \%$ & 268 \\
Total & 3254 & $2,06 \%$ & 67 & $10,36 \%$ & 337 & $6,48 \%$ & 211 & $59,80 \%$ & 1946 & $19,45 \%$ & 633 \\
\hline
\end{tabular}

Ressalte-se que apenas parte da amostra pôde ser analisada, visto que os editais de atletas contemplados deixaram de apresentar esta informação a partir dos anos conseguintes a 2008. Nesta tabela também é visível a configuração do campo esportivo próxima ao econômico. Se analisarmos o PIB (Produto Interno Bruto) das regiões no ano de 2010 publicado em 2012 pelo IBGE (Instituto Brasileiro de Geografia e Estatística), será paralelo ao gráfico desenhado para a distribuição dos atletas: 


\section{Gráfico 2. Comparação entre o PIB e a distribuição regional dos atletas beneficiados}

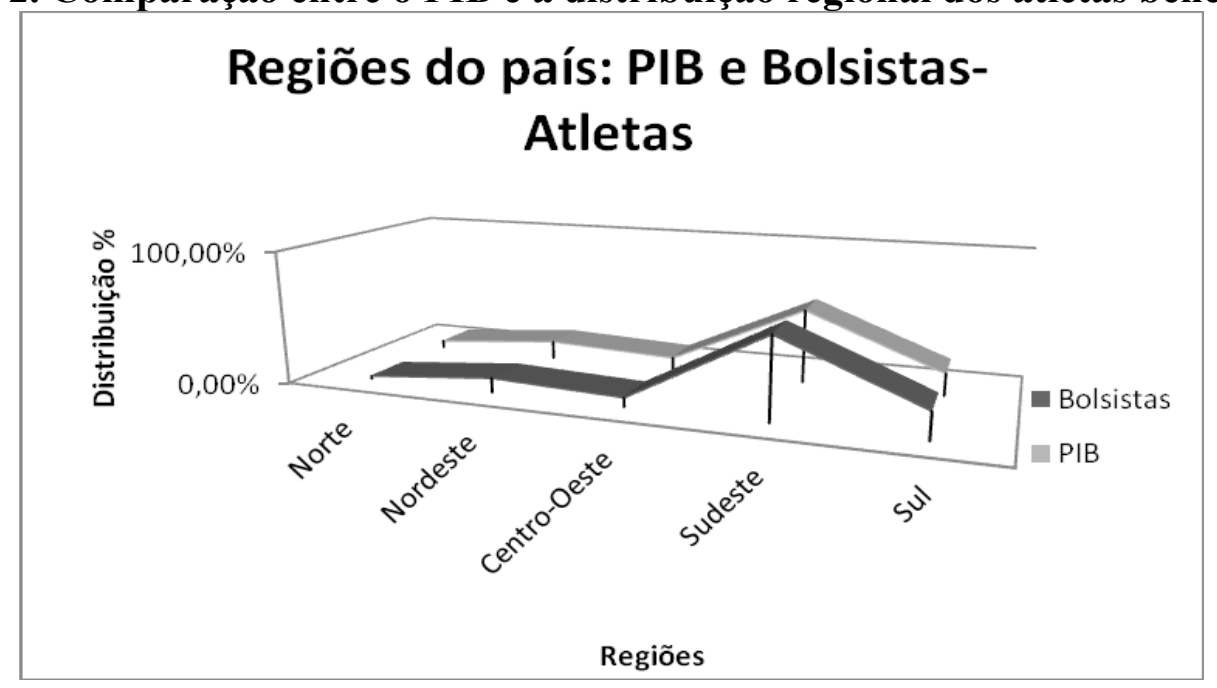

Podem-se obter os dados percentuais de cada um na tabela a seguir:

Tabela 5. Distribuição percentual dos valores obtidos do PIB e dos bolsistas do programa por regiões.

\begin{tabular}{c|c|c|c|c|c}
\hline & Norte & Nordeste & Centro-Oeste & Sudeste & Sul \\
\hline Bolsistas & $2,10 \%$ & $10,55 \%$ & $6,61 \%$ & $60,93 \%$ & $19,82 \%$ \\
PIB & $5,30 \%$ & $13,50 \%$ & $9,30 \%$ & $55,40 \%$ & $16,50 \%$ \\
\hline
\end{tabular}

Nota-se que há certa proximidade entre ambos. Atletas que se concentram nas regiões mais desenvolvidas economicamente têm maior probabilidade de galgar um rendimento ao alto nível, em decorrência da infraestrutura, de competições mais corriqueiras, maior número de patrocinadores, enfim, uma série de fatores que acabam por privilegiar o destaque dos atletas das regiões mais ricas. Do total de 3.254 bolsas, a Região Sudeste teve mais da metade dos atletas beneficiados. Tal observação permite os seguintes questionamentos: Por que isso ocorre? Será que a construção de centros de treinamento contemplando as cinco regiões do país promoverá uma distribuição mais equitativa? Ou a configuração só se modificará a partir do desenvolvimento econômico das demais regiões?

\section{Conclusões}

Ao concluir esta primeira análise dos dados observa-se que há muito que investigar acerca do programa. Ele representou um avanço inegável ao esporte brasileiro, pois foi a primeira política federal que beneficiou financeiramente o atleta e não somente as instituições que organizam e controlam o esporte nacional. 
Por fím não se poderia deixar de destacar a importância de se ampliar a "BolsaAtleta" para as categorias de iniciação esportiva de rendimento, principalmente na categoria Base. Para sanar essa questão, existe atualmente em tramitação no Plenário da Câmara dos Deputados um Projeto de Lei (no 4.680/2012), de autoria do deputado Danrlei de Deus, que altera a redação do inciso I do art. 3 da lei do Bolsa-Atleta, reduzindo para nove anos a idade mínima para obtenção do benefício. Porém, mais do que essa alteração, o que é necessário para o país conseguir cumprir com seus objetivos para esses megaeventos que serão sediados aqui é uma modificação do sistema esportivo brasileiro, antes que ele tombe de vez por falta de base que o sustente...

Ao longo deste estudo muitas questões relevantes puderam ser feitas (ou ficaram por se fazer); nem todas almejaram uma resposta, porém, estas não se silenciarão ao ponto final desta redação. A esperança é que tais questões ressoem nas mentes daqueles responsáveis pela gestão do esporte brasileiro e consigam promover uma minimização das falhas que o programa analisado reflete do que vem a ser o sistema esportivo brasileiro.

BRAZILIAN SUMMER OLYMPIC SPORT FINANCING: INITIAL MAPPING OF THE “ATHLETE-ALLOWANCE” PROGRAM (2005-2011)

\begin{abstract}
The present research has the objective of conducting an initial mapping of an important Federal Government program of promoting Brazilian sport called "Athlete-Allowance". Therefore, the sources used at the analysis were the lists of contemplated athletes available on the website of the Sport Ministry, between 2005 and 2011. From these sources information referring to Summer Olympic sport modalities were taken, totaling a number of 9,149 allowances granted. As a conclusion, the research indicates that the "Athlete-Allowance", even bringing innumerable benefits to the Brazilian Olympic sport, still reflects a pyramid with a narrow foundation, with instabilities that weaken it to the point of not being able to "stand on its own".
\end{abstract}

Keywords: Sports. Government financing. Athletes.

\title{
FINANCIACIÓN OLÍMPICO BRASILEÑO DE DEPORTES DE VERANO: MAPEO INICIAL DEL "BECA ATLETA" (2005-2011)
}

\section{Resumen}

El presente estudio tiene como objetivo llevar a cabo un mapeo inicial de un programa federal importante para promover el deporte brasileño: denominado "Beca Atleta". Por lo tanto, la fuente utilizada en el análisis fueron las listas de los atletas disponibles en el sitio del Ministerio de Deporte, acotada entre los años 2005-2011. Estas fuentes se seleccionaron información con respecto a las modalidades de los deportes olímpicos de verano, con un número total de 9.149 becas. En conclusión, la investigación muestra que la "Beca Atleta", aunque esto trae numerosos beneficios para el deporte olímpico brasileño, todavía pirámide refleja una estrecha cama, con las inestabilidades que lo debilitan hasta el punto en que no podía seguir el ritmo del "pie".

Palabras-claves: Deporte. Financiamiento gubernamental. Atletas. 


\section{Referências}

BRASIL. Lei no 10.891, de 9 de julho de 2004. Institui a Bolsa-Atleta.

. Decreto-Lei no 5.342, de 14 de janeiro de 2005. Regulamenta a Lei no 10.891 , de 9 de julho de 2004, que institui a Bolsa-Atleta.

. Lei no 12.395, de 16 de março de 2011. Altera as Leis $n \underline{\mathrm{OS}} 9.615$, de 24 de março de 1998, que institui normas gerais sobre desporto, e 10.891, de 9 de julho de 2004, que institui a Bolsa-Atleta; cria os Programas Atleta Pódio e Cidade Esportiva; revoga a Lei no 6.354 , de 2 de setembro de 1976; e dá outras providências.

. Decreto no 7.802, de 13 de setembro de 2012. Altera o Decreto $n \underline{0} 5.342$, de 14 de janeiro de 2005, que regulamenta a Lei no 10.891 , de 9 de julho de 2004, que institui a Bolsa-Atleta.

. Projeto de Lei no 4.680, de 7 de novembro 2012. Altera o inciso I do art. 3o da Lei $\mathrm{n}^{\circ}$ 10.891, de 9 de julho de 2004, que institui o Bolsa-Atleta, alterado pela Lei no 12.395, de 16 de março de 2011.

CORREAA, A. J. Financiamento do esporte olímpico brasileiro: mapeamento inicial do programa "Bolsa-Atleta". 86f. Monografia (Graduação em Educação Física) - Departamento de Educação Física, Universidade Federal do Paraná, Curitiba, 2013.

GREEN, M.; HOULIHAN, B. Elite sport development: policy learning and political priorities. London: Routledge, 2005.

GREEN, M.; OAKLEY, B. Elite sport development systems and playing to win: uniformity and diversity in international approaches. Leisure Studies, v. 20, p. 247-267, 2001.

HENRY, I. et al. A typology of approaches to comparative analysis of sports policy. Journal of Sport Management, v. 19, p. 520-535, 2005.

HOULIHAN, B. Sport and society. London: Sage Publications, 2008.

INSTITUTO BRASILEIRO DE GEOGRAFIA E ESTATÍSTICA (IBGE). Contas regionais do Brasil 2010. Rio de Janeiro: IBGE, 2012.

GUIMARÃES, A. S. A Bolsa-Atleta eleva o desempenho de seus beneficiários? Análise do período 2005-2008. Brasília: Senado Federal, 2009. (Texto para Discussão, 50).

SHIBLI, S.; BINGHAM, J. A forecast of the performance of China in the Beijing Olympic Games 2008 and the underlying performance management issues. Managing Leisure, v. 13, n. 3-4, p. 272-292, 2008. 
STAREPRAVO, F. A. Políticas públicas de esporte e lazer no Brasil: aproximações, intersecções, rupturas e distanciamentos entre os subcampos políticos/burocráticos e científico/acadêmico. 2011. 422 f. Tese (Doutorado em Educação Física) - Programa de PósGraduação em Educação Física, Universidade Federal do Paraná, Curitiba, 2011.

Recebido em: 20/03/2014

Revisado em:14/07/2014

Aprovado em: 20/08/2014

Endereço para correspondência:

moraes_marc@yahoo.com.br

Marcelo Moraes e Silva

Universidade Federal do Paraná - Rua XV de Novembro, 1299 |

CEP 80.060-000 - Centro | Curitiba | PR | Brasil | 